\title{
A spatial analytical approach towards understanding racial residential segregation in Gauteng province (South Africa)
}

\author{
Samy Katumba ${ }^{\text {a,d, }}$, Inger Fabris-Rotelli ${ }^{b}$, Alfred Stein ${ }^{\text {b,c }}$, Serena Coetzee ${ }^{\mathrm{d}}$ \\ ${ }^{a}$ Gauteng City-Region Observatory, Johannesburg, South Africa, samy.katumba@ gcro.ac.za \\ ${ }^{b}$ Department of Statistics, University of Pretoria, Pretoria, South Africa, inger.fabris-rotelli@up.ac.za \\ ${ }^{c}$ University of Twente, The Netherlands, a.stein@utwente.nl \\ ${ }^{d}$ Department of Geography, Geoinformatics and Meteorology, University of Pretoria, Pretoria, South Africa, \\ serena.coetzee@up.ac.za \\ * Corresponding author
}

Keywords: segregation, spatial information theory index, diversity, MAUP

Abstract:

The introduction of apartheid in 1948 resulted in racial residential segregation that has influenced the spatial distribution of the population in South Africa. Apartheid laws, which were mainly based on race, brought about the exclusion of the non-white population from urban areas and the mainstream economy of South Africa, as well as the benefits that come with it. In the early 1990's, apartheid was abolished and the South African government set to bring about social and spatial justice, address inequalities and promote social cohesion. This also meant doing away with racial residential segregation that had been entrenched into the urban morphology of the country. Despite this, in the post-apartheid era, racial-residential segregation still exists (Parry and Van Eeden 2015).

Figure 1 shows the density (kernel) distribution of each of the four population groups in Gauteng in 2011: Indian/Asian (IA), white (W), black African (BA) and coloured (C). It is a reflection of the legacy of apartheid town planning which isolated non-whites to the peripheral areas of urban economic centers. Densely populated areas are coloured in red while less populated areas are coloured in green. As it can be seen in the map (Figure 1), the white population group densely occupies areas close to the business centers of the province in places such as Pretoria and northern parts of Johannesburg, while non-whites densely occupy peripheral areas in former townships designated to non-whites, such as Soweto (black African), Mabopane (black African) and Lenasia (Indian/Asians). This observed pattern is more pronounced for black Africans.
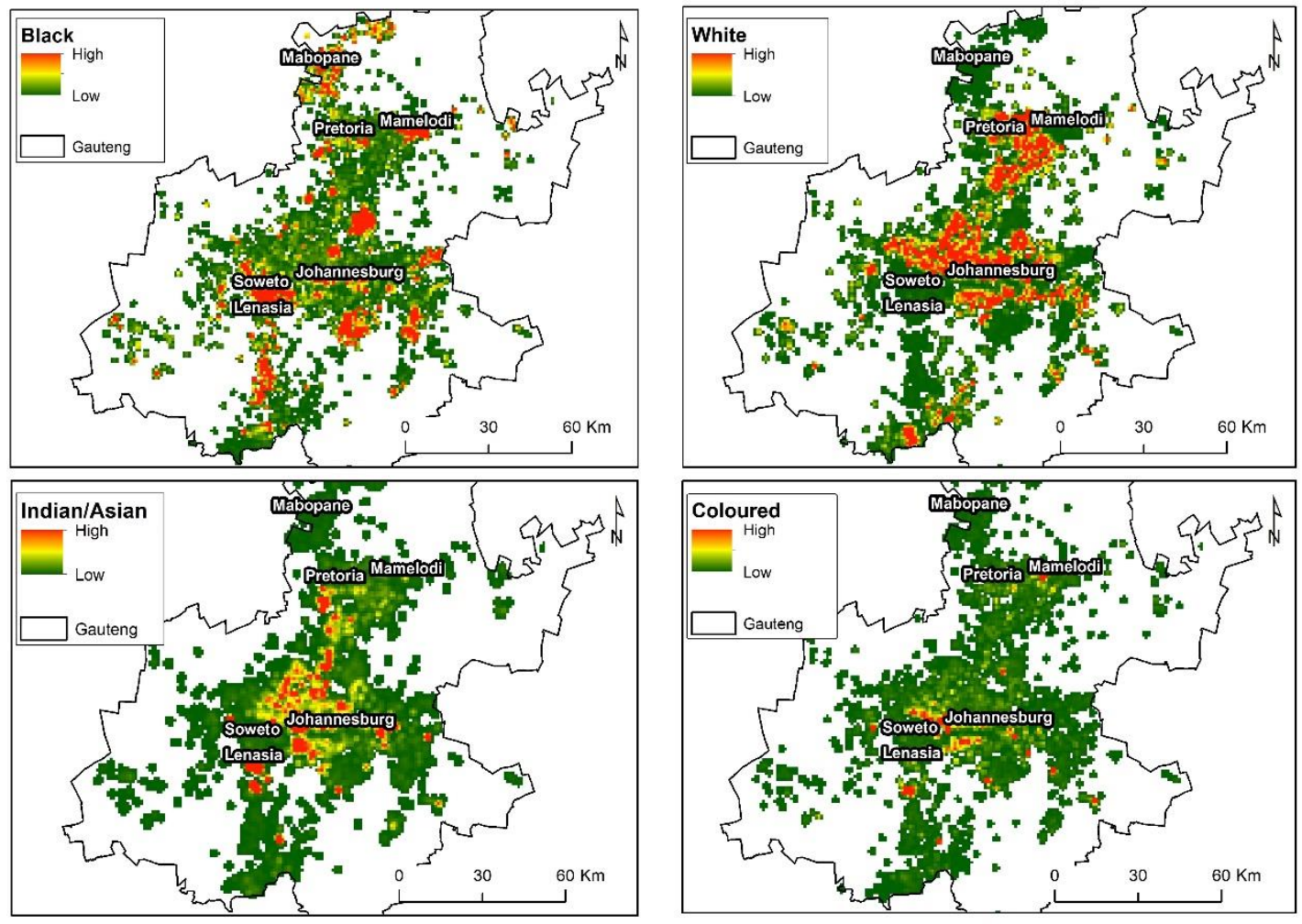

Figure 1. Population distribution based on StatsSA census 2011. 
To study the pattern of racial residential segregation in South Africa, non-spatial indices of segregation are widely employed despite their shortcomings. Parry and Van Eeden (2015) are among the few authors who have acknowledged the importance of employing spatial indices of segregation, even though they did not explicitly use one due to the lack of ready to use GIS software. Massey and Denton (1988) define residential segregation as "the degree to which two or more groups live separately from one another, in different parts of the urban environment", i.e. racial residential segregation manifests itself across space. Hence, in order to assess the extent to which the levels of racial residential segregation have subsided, adequate empirical studies that employ spatial segregation indices on socio-economic data are necessary. The purpose of this research is to study the pattern of racial residential segregation by employing a spatial index of segregation namely the 'spatial information theory index $(\mathrm{H})$ ' for Gauteng province, the economic hub and most populated province of South Africa.

Some of the shortcomings of existing non-spatial indices of segregation (and also of some of the spatial ones) include the Modifiable Areal Unit Problem (MAUP) which refers to how such indices are sensitive to the size of the areal units (i.e. administrative or political boundaries) of analysis that might be arbitrarily chosen or might not accurately reflect the actual racial composition of the local neighbourhoods. This introduces possibilities of obtaining inaccurate measures of racial residential segregation and also being unable to compare the results at various scales of analysis (Reardon et al. 2004; Weir-Smith 2016). One of the major challenges that impedes the use of spatial segregation indices is the lack of ready to use software that has implemented spatial segregation indices which have attempted to address the MAUP. To address such a challenge, Hong et al. 2014 implemented a series of spatial equivalences of existing segregation measures in R under the package 'seg' based on Reardon et al. (2004)'s formulation of spatial segregation indices. Reardon et al. (2004) emphasise the computation of spatial indices of segregation based on the racial composition of the population as reflected by their immediate local environment instead of relying on arbitrary or fixed administrative boundaries. The 'spatial information theory index $(\mathrm{H})$ ' as implemented by Reardon et al. (2004) is experimented in this study.

This study explores existing literature related to racial residential segregation in order to further complement and supplement existing theories on segregation in South Africa by adopting a spatial analytical approach. The authors take advantage of the R implementation of spatial measures of segregation (Hong et al. 2014), namely the spatial information theory index $(\mathrm{H})$, to study the patterns of residential segregation in Gauteng province (South Africa).

The 2011 Census data for the Gauteng province, aggregated at the sub-place (neighbourhood) level, was used to measure residential segregation based on four racial population groups. The racial composition of the local environment was computed at four different values of radii: $r=200 \mathrm{~m}, 500 \mathrm{~m}, 1000 \mathrm{~m}, 2000 \mathrm{~m}$ and $4000 \mathrm{~m}$, respectively (see Table 1). These values correspond to distance ranges from pedestrian walking to larger extent across neighbourhoods. The values of the spatial information theory index that quantify racial residential segregation are represented by $H$ (see Table 1 ). A total number of 2579 subplaces (neighbourhoods) was considered in the analysis.

\begin{tabular}{|l|l|l|l|l|l|}
\hline$r$ & $200 \mathrm{~m}$ & $500 \mathrm{~m}$ & $1000 \mathrm{~m}$ & $2000 \mathrm{~m}$ & $4000 \mathrm{~m}$ \\
\hline$H$ & 0.565 & 0.565 & 0.558 & 0.523 & 0.446 \\
\hline
\end{tabular}

Table 1. Spatial information theory index $(H)$ results

Complete racial integration corresponds to $H=0$ and there is complete racial segregation if $H=1$. As it can be observed in Table 1, when the maximum distance is between $200 \mathrm{~m}$ and $500 \mathrm{~m}$ the value of $H$ is 0.565 . However, as the maximum distance value increases, the value of the $H$ decreases. This implies that the levels of segregation are high when the area of the local environment is small and low when the opposite is true. Such an outcome corroborates some of the findings in the literature that suggest that the levels of segregation are low at large scales (Parry and Van Eeden 2015). Nevertheless, by following the methodology employed in this study, the obtained results are marginally affected by the MAUP and other shortcomings that affect non-spatial indices of segregation. This is because one is able to determine the extent of the study area and thereby computes the levels of segregation of the true racial composition instead of being constrained by arbitrary administrative or political boundaries.

In future, instead of limiting the calculation of segregation indices at specific distances, this work could be extended by computing local spatial indices of segregation (e.g. for each subplace) by following the methodology proposed by Chodrow (2017).

\section{References}

Chodrow, P.S. (2017). Structure and Information in spatial segregation. Proceedings of the National Academy of Sciences of the United States of America (PNAS), Vol. 114, No. 44, October 31, 2017.

Hong, S.Y., O’Sullivan, D. and Sadahiro, Y. (2014). Implementing Spatial Segregation Measures in R. PLOS ONE 9(11): e113767. Doi:10.1371/journal.pone.0113767.

Massey, D.S. and Denton, N.A. (1988). The dimensions of residential segregation. Social Forces, 67 (2), 281 -315. 
Parry, K. and Van Eeden, A. (2015). Measuring racial residential segregation at different geographic scales in Cape Town and Johannesburg, South African Geographical Journal, 97 (1), 31 - 49.

Reardon, S.F. and O’Sullivan, D. (2004). Measures of Spatial Segregation, Sociological Methodology, 34, 121 - 62.

Weir-Smit, G. (2016). Changing boundaries: Overcoming modifiable areal unit problems related to unemployment data in South Africa. South African Journal of Science, 112 (3/4), pp1-8. 